\title{
The Effects of Apologies for Service Failures in the Global Online Retail
}

\author{
Sanchayan SENGUPTA \\ Daniel RAY \\ Olivier TRENDEL \\ Yves VAN VAERENBERGH
}

Forthcoming in International Journal of Electronic Commerce

\section{Author information-}

Sanchayan SENGUPTA * Department of Strategies and Markets, ESSCA, Ecole de Management, 7 Rue Curie, 69006 Lyon, France. Email: sanchayan.sengupta@essca.fr,

Tel. +33665313725

Daniel RAY, Department of Marketing, Grenoble Ecole de Management, 12 Rue Pierre Semard, 38000 Grenoble, France. Email: daniel.ray@grenoble-em.com, Tel. +33 476706030

Olivier TRENDEL, Department of Marketing, Grenoble Ecole de Management, 12 Rue Pierre Semard, 38000 Grenoble, France. Email: olivier.trendel@grenoble-em.com, Tel. +33 4767065 25

Yves VAN VAERENBERGH, Department of Marketing, KU Leuven, Warmoesberg 26, 1000 Brussels, Belgium. Email: yves.vanvaerenbergh@kuleuven.be, Tel. +32 26098274.

\footnotetext{
${ }^{*}$ Corresponding author
} 


\section{Author biographies:}

Sanchayan Sengupta is an Assistant Professor of Marketing at ESSCA Ecole de Management, France. His research interests are in services marketing, complaint management and crosscultural research. His research has appeared in several conference proceedings including Academy of Marketing Science Annual conference, 2016.

Daniel Ray is a Professor of Marketing and Director of Customer Equity Institute at Grenoble Ecole de Management. He received his Ph.D. in marketing from the University of Paris I Panthéon Sorbonne. Prior to entering academia, he had worked in senior levels in consulting and market research firms like TNS-Sofres and EY. His research deals with customer satisfaction and technological innovation in marketing. His publications have appeared inM@n@gement, Recherche et Applications en Marketing and Decisions Marketing. He is the author of two books that have received three awards.

Olivier Trendel is an Associate Professor of Marketing at Grenoble Ecole de Management in France. He received his Ph.D. in marketing from the University of Grenoble. His main areas of research concern the study of automatic mechanisms of information processing (i.e., implicit cognition), mechanisms that drive spontaneous beliefs and behaviors. The domains of applications include communication effectiveness, food consumption, and relational marketing. His research has been published in Appetite, Food Quality and Preference, Journal of Business Research, Journal of Marketing Research, and Recherche et Applications en Marketing. He serves on the editorial board of Recherche et Applications en Marketing.

Yves Van Vaerenbergh is an Assistant Professor of Marketing at the department of marketing, KU Leuven in Belgium. He received his Ph.D. in applied economics from the Center for Service Intelligence at Ghent University. His research interests include mainly service issues, such as service failures, service recovery, pricing innovations like access-based services, and metaanalysis. His publications have appeared in Academy of Management Perspectives, Journal of Service Research, and Journal of Business Research, among others. He has received several best-reviewer awards and best-paper awards from service journals, and serves on the editorial boards of the Journal of Service Research, Journal of Business Research, Journal of Service Management and the Journal of Service Theory and Practice. 


\title{
The Effects of Apologies for Service Failures in the Global Online Retail
}

\begin{abstract}
Virtually all sources on service recovery stress the importance of offering an apology to complaining customers. To date, however, our understanding of who should offer the apology, and how to offer the apology is still limited. Taking a cross-cultural perspective, Study 1 shows that Eastern customers attach more value to a manager (vis-à-vis a frontline employee) offering an apology than Western customers in an offline retailing context, but not in an online retailing context. In an online setting, study 2 further extends these insights by showing that the status of service personnel matters for Eastern customers, but only if the apology is provided publicly on social media and not if the apology is provided online privately. Global e-commerce managers can benefit from these findings when developing their service recovery strategies. By demonstrating that recovery strategies that are proposed and tested in offline are nontransferrable to online, this paper provides a clearer understanding of service recovery across online and offline channels. Based on face theory, this research highlights the public versus private nature of an apology in a global, online retailing context thus contributing to the emerging research in online service recovery.
\end{abstract}

Keywords: service failure, service recovery, apology, e-commerce, culture, perceived justice. 


\section{The Effects of Apologies for Service Failures in the Global Online Retail}

\section{Introduction}

Every day, customers across the globe complain to firms about online service failures. For example, $46 \%$ of British customers complained about their online purchases over a two-year period (2012-2014); similar figures have been reported in other countries [62]. Due to increased globalization, firms face the challenge of responding to complaints of customers with varying cultural backgrounds $[49 ; 53]$. Given the increasing number of complaints coming from diverse group of customers, managers need an understanding of how they can respond optimally to customer complaints, and to what extent their responses need to be adapted to cultural influences.

One of the clearest recommendations in service recovery literature is that organizations should apologize for service failures. Offering an apology generally increases perceived justice, and hence, customer outcomes (e.g., [15; 40]). Researchers also outline cross-cultural differences in customer evaluations of an apology. For example, Wong [71] shows that offering an apology matters for Singaporean and Australian customers, but not for U.S. customers as they prefer a compensation (see also [29]). Yet, existing literature relating to cross-cultural service recovery almost exclusively concerns offline contexts and not online and low contact contexts across the globe [48]. However, the worldwide surge of B2C ecommerce sales and cross-border transactions $[1 ; 32]$ creates the challenge for online retailers to deliver excellent customer experiences $[33 ; 9]$.

Previous research shows that behavior of customer-contact employees impacts customer satisfaction with online service encounters [43]. In case of a service failure, the literature provides very limited insights into who should apologize. To the best of the authors' knowledge, only Patterson, Cowley, and Prasongsukarn [50] show that customers high in power distance 
(e.g., Thais) value an apology delivered by high-status personnel more than an apology delivered by low-status personnel, whereas customers low in power distance (e.g. Australians), appear to be indifferent to the personnel's status [50]. In an online context, the issue of who should apologize for a service failure seems to be ignored. This research studies the role of service personnel status (e.g., Manager vs. Agent) on justice perception in online versus offline context, and examines how this relationship depends on the cultural background of customers. We argue that, due to the mediating role of technology $[28 ; 39 ; 68]$, existing offline findings regarding cross-cultural service recovery practices cannot be directly applied to online contexts.

Using face theory [23] as a theoretical anchor, this paper offers two main contributions to the literature. First, contrary to Patterson et al.'s [50] findings in an offline face-to-face hospitality services context, we show that, in an online context, the status of the contact personnel does not matter for both Eastern and Western customers. This is because unlike offline encounters between customers and service providers that are mostly public in nature [17;20], online encounters are often private (e.g., when using emails). Therefore 'face' is activated in offline and not in online environment. Second, this paper shows that, counterintuitively, service firms can still activate 'face' in online, low contact encounters under certain conditions like offering a public online apology on social media. More specifically, for Eastern customers, the status of the contact personnel matters if the apology is provided online publicly (e.g., using twitter), but not if the apology is provided privately (e.g., using emails). As such, this paper shows that the public versus private nature of an online apology offered by high-status contact personnel drives customer reactions after service failure.

Overall, this paper enhances the understanding of service recovery in an increasingly global and online market [48]. Understanding how organizations can customize their service offerings 
in a global market was listed recently as a service research priority [49]. Our findings are therefore relevant to managers of online organizations who operate globally and/or cater to customers that belong to multi-cultural backgrounds.

\section{Theoretical Background and Hypothesis Development}

A successful service recovery not only reduces negative behaviors (e.g., churn, negative word of mouth, retaliation) but also increases positive ones (e.g., repurchase intention, positive word of mouth, increase expenses) [34; 48; 52; 65]. For instance, Knox and Van Oest [34] found that, compared to unsuccessful service recoveries, successful recoveries reduced likelihood of customer departure by 27 percent (from 67\% to 40\%) and increased customer spending by $\$ 38$ on average. An important step toward a successful recovery is to apologize to customers for service failures [14]. As service failures cause both psychological and financial loss, offering an apology represents an acknowledgement to the customer that there indeed is a problem and that the organization is serious about solving it [4]. Apology is thus a form of psychological compensation mechanism helping customers in restoring equilibrium [11]. Many studies obtained that complaining customers who receive an apology are more satisfied than customers who receive no apology (e.g., [55; 70]).

Offering an apology restores customer satisfaction through justice perceptions [55]. In service recovery, customers evaluate justice from three dimensions that relate to fairness of interactional treatment provided by the service personnel (interactional justice), fairness of the policies and procedures implemented by the company (procedural justice), and fairness of the redress offered (e.g., a refund; distributive justice) [48; 57; 61]. As personnel status is our main variable of interest, our research focuses on interactional justice because it is the dimension of justice that specifically addresses the human factor, i.e., the contact personnel behaviors and 
characteristics $^{1}[7 ; 8]$. Meta-analyses have confirmed the impact of interactional justice on satisfaction [8; 48], and some studies have even insisted on its larger effect on customer outcomes than distributive or procedural justice [61].

Status of the service personnel should not influence procedural and distributive justice. Procedural justice concerns policies and procedures set by the company to handle complaints, and the personnel that implement them often do not have the freedom to change them $[59 ; 12]$. Distributive justice is centered on the fairness of the redress or compensation offered to the customer, and, as such, does not directly concern contact personnel characteristics such as status [48]. The view that procedural and distributive justices don't encompass the human part of service recovery is also consistent with the historical development of justice theory: the interactional justice dimension has been introduced to dissociate the human factor from the procedural aspects of the service recovery process $[7 ; 8]$.

In an online retailing context, the focus of this paper, the interactional part of service recovery should be largely impacted by the mediating role of technology $[68 ; 28 ; 67]$. Interactional justice has been further decomposed in two dimensions, namely interpersonal treatment (politeness and courtesy provided during face-to-face interaction) and informational justice (adequacy and truthfulness of information provided for the failure) [7]. Because of the absence of face-to-face interpersonal interaction in online settings [68; 28], our study specifically focuses on informational justice. Indeed, compared to face-to-face communication, computermediated communication profoundly changes the way of interacting [24; 68]. While face-to-face interactions greatly rely on spoken language and visible social cues such as nonverbal gestures, communication in computer-mediated contexts often depends on such features as written text

\footnotetext{
${ }^{1}$ We nevertheless also provide the results on the other dimensions of justice.
} 
messages. Because of the lack of interpersonal cues in online contexts, past research has shown that consumers tend to fill in the blanks with regards to missing information, which renders informational justice particularly important in this context [68].

Researchers and managers should be careful in generalizing service recovery findings from Western to Eastern contexts. Existing research shows that cultural traits have an impact on how customers use information technology in services [37]. Researchers further show that cultural values influence how customers evaluate their service encounters and form fairness perceptions about recovery $[13 ; 50]$. These studies typically investigated the impact of two specific cultural orientations: power distance (i.e., the extent to which the less powerful members of a society accept that power is distributed unequally among them) and individualism-collectivism (i.e., the degree of interdependence a society maintains within its members). For instance, Patterson et al. [50] show that power distance influences customer's interaction with the service provider based upon the status of the service personnel performing the recovery: Customers from Eastern cultures receiving an apology from a high-status employee have higher justice perceptions as compared to Western customers.

Compared to Western customers, customers in Eastern societies belong to cultures that have large power distance and are collectivistic [25]. Such customers have clear demarcations between in-groups and out-groups; they have strong in-groups that they trust. These customers consider the service personnel as an out-group member and feel a sense of loss due to this outgroup in case of service failure [64]. The in-group customers will evaluate the recovery performed by the service personnel based on the extent to which the recovery restores the complaining customer's image vis-à-vis the members of the customer's in-group. The 'face' concept provides the rationale behind this formation of justice perception. Face of an individual 
is "the respectability and/or deference which a person can claim for himself from others by virtue of his relative position" [23, page 883$]$ and therefore refers to how an individual perceives the way the people in the society or in the immediate vicinity view him or her [21;33]. As the public reflection of the individual's self-image [47], face is considered very important in Eastern cultures [50]. In cross-cultural service recovery, this face concept will be a salient component of customers in Eastern collectivistic societies with large power distance as compared to Western customers [25].

This reasoning is also consistent with the level of context of Eastern versus Western cultures. In high-context cultures, "most of the information is either in the physical context or internalized in the person while very little is in the coded, explicit, transmitted part of the message", while in low-context cultures most of the information is held in an explicit code [18]. Typically, Western societies are low-context cultures and Eastern societies high-context cultures [46]. In high-context cultures, disagreeing with other people publicly may lead to loss of face whereas in low-context cultures, disagreements are more linked to the issue and not to the person, thus not impacting face [63]. Moreover, in conflict situations, people in Eastern, highcontext cultures prefer non-confrontation whereas in Western, low-context cultures people generally prefer solution-based resolution of conflicts [5]. Eastern customers should thus rate the apology of a high-status employee (e.g. a manager) more favorably than the apology of a lower status employee (e.g. a cashier). For Westerners, the status of the employee offering the apology should not matter [50].

This paper posits that these effects occur in an offline, high-contact setting, but not in an online setting. Patterson et al. [50] suggest that complaining customers' desire to restore or gain face leads them to value an apology from a person high in status more than an apology from a 
lower ranked employee. In an offline, face-to-face setting, the public nature of an apology given by the service provider is visible to people in society or in the immediate vicinity. The status of the personnel offering the apology restores face of the customer and enhances his or her social standing, leading to higher justice perceptions. The public nature of the exchange thus forms a necessary condition for face to be activated [47]. But commonly used online complaint channels, like email, are typically private. Who offers the apology then becomes less visible, and the status of the personnel offering the apology will be less likely to affect customers' justice perceptions.

The evidence from communication context literature, notably Mehrabian [44], shows that the non-verbal part of any communication plays a vital role in forming perceptions about the conveyed message in the receiver's mind [44]. As this part is missing in online service recovery, the same effect that was observable in a face-to-face interaction may not be observed here [24].

In summary, the non-verbal communication aspect along with the face concept is expected to impact justice perceptions in offline but not in online context. Based on face theory, the status of service personnel is expected to affect informational justice perceptions in an offline but not in an online context. As face is mainly a concern for Eastern collectivistic societies with large power distance, we expect a moderating effect of culture on the relationship between status of service personnel and informational justice. We thus hypothesize a 3-way interaction between status of service personnel, complaint channel and culture:

H1: Culture moderates the interactive effect between status of service personnel and complaint channel, such that:

H1a: Customers in Eastern cultures will have higher perceptions of informational justice when offered apology from high status as compared to low status service personnel in offline but not in online context. 
H1b: Customers in Western cultures will be indifferent to the status of the service personnel providing the apology in forming informational justice perceptions in offline as well as in online context.

While the aforementioned reasoning applies to online contexts that are mainly used privately, in recent years researchers and practitioners have witnessed a proliferation of new media, which fundamentally change the nature of relationships between organizations and their customers [22]. As more and more customers complain to or about organizations using these new media [60], organizations need an understanding of how to manage service recovery on these online channels [36]. One characteristic of these new media, relevant to the context of this study, is that they allow communication occurring both publicly and privately. For example, Hennig-Thurau et al. [22] note that "consumers' new media activities can be seen by others" [22, page 312$]$. Hence, managers need to decide on whether they respond publicly or privately to customer complaints. Commonly used complaint channels like Twitter and Facebook, for example, allow communication that is public (e.g. directly on the Facebook wall or the Twitter feed) or private (e.g. the direct message - DM option).

Our first hypothesis proposed that Eastern customers would react more positively to a manager apologizing for a service failure rather than a "regular" employee, but only in an offline setting and not in an online setting. The basic rationale was that the public nature of the exchange forms a necessary condition for face to be activated [47]. If the public versus private nature of an apology is the root cause of these effects, then the hypothesized effects should also occur in a public online channel but not in a private online channel. However, for Western customers, as face will not likely be activated for such customers, the private versus public apology mode 
should not be relevant in forming service evaluations. Hence, the second hypothesis provides a more stringent test of the process underlying the first hypothesis. We propose:

$\mathrm{H} 2$ : Culture moderates the interactive effect between status of service personnel and apology mode (public vs. private), such that:

H2a: In an online context, customers in Eastern cultures will have higher perceptions of informational justice when offered apology from high status as compared to low status service personnel if the apology is provided publicly but not privately.

$\mathrm{H} 2 \mathrm{~b}$ : In an online context, customers in Western cultures will be indifferent to the status of service personnel in forming informational justice perceptions, and that whatever the apology mode (public vs. private).

Extant research has shown that justice perception is an antecedent of recovery satisfaction such that justice mediates the relationship between recovery attributes and recovery satisfaction [48; 52]. Because status of service personnel should only influence informational justice for Eastern customers if the apology is provided publicly (cf. H2), we hypothesize:

H3a: For customers from Eastern cultures, apology mode (public vs. private) will moderate the indirect effect of status of service personnel on recovery satisfaction through perceived informational justice. Specifically, informational justice will mediate the indirect effect when the apology is provided publicly but not when the apology is provided privately.

H3b: For customers from Western cultures, apology mode (public vs. private) will not moderate the indirect effect of status of service personnel on recovery satisfaction through perceived informational justice. Informational justice will not mediate the indirect effect, and that both when the apology is provided publicly and privately. 


\section{Overview of Studies}

Two experiments, using samples from four different countries (Germany and United States for Western consumers; India and Philippines for Eastern consumers), tested the three hypotheses of the paper. Experiment 1 tested H1 by comparing offline and online environments. Experiment 2 focused on an online environment and tested $\mathrm{H} 2$ and $\mathrm{H} 3$ using Twitter, the preferred social media channel for service complaints [42]. Figure 1 presents the conceptual model of the research.

\section{[Figure 1 here]}

Because for customers from Western cultures our hypotheses are in fact null hypotheses (i.e., $\mathrm{H} 1 \mathrm{~b}, \mathrm{H} 2 \mathrm{~b}$ and $\mathrm{H} 3 \mathrm{~b}$ ), we performed a power analysis to show that the sizes of the samples were large enough to provide evidence in favor of null hypotheses. When the goal of a research is to accept a null hypothesis, Cohen [6] recommends using a power of .90 . Considering the minimum sample size used (i.e., 398 participants in Study 1), the studies were able to detect an effect size $f=.17$ with a power of .90 . This effect size lies between a small $(f=.10)$ and a medium $(f=.25)$ effect size for Analyses of Variance [6] and is smaller than the effect sizes found in previous studies dealing with service recovery in a cross cultural context (e.g., [50]). Hence, in our studies, a failure to reject a null hypothesis most likely cannot be attributed to a lack of power.

\section{Study 1}

\section{Design and Participants}

The first study was designed to test the first hypothesis. Two-hundred seventeen German $\left(67 \%\right.$ male; $M_{\text {age }}=34.2$ years, $\left.S D=10.9\right)$ and two-hundred fourteen Indian $\left(74 \%\right.$ male; $M_{\text {age }}=$ 29.6 years, $\mathrm{SD}=10.1)$ consumers participated in a 2 (status of service personnel: high vs. low) $\mathrm{x}$ 
2 (complaint channel: offline vs. online) x 2 (culture: Western vs. Eastern) between-subject study design. Participants were recruited from Crowdflower crowdsourcing platform (www.crowdflower.com), and were paid $\$ 1.20$ (Germany) and $\$ 1.00$ (India) for their participation. Recent articles on using web-based paid crowdsourcing samples for data collection in social science research have pointed out the suitability of using such samples in terms of data quality and reliability (e.g., $[30 ; 41])$.

Germany (power distance: 35, individualism: 67) and India (power distance: 77, individualism: 48) have contrasting values in Hofstede's [25] national power distance and individualism-collectivism dimensions, making them suitable for the research purposes. Twentyone participants from the German sample and 18 participants from the Indian sample were removed from the analyses as they failed to precisely remember whether the scenario concerned online or offline shopping, leaving 196 German and 196 Indian participants in the final sample ${ }^{2}$. The significance and directionality of the results hold when these participants are not removed from the analyses.

\section{Procedure}

For German participants, the survey was presented in German language while for Indian participants the survey was presented in English. The use of English as the survey language in India is appropriate as English is one of the official languages; 2013 Pearson BEI Survey [51] that ranks countries in terms of Business English proficiency ranked India among the top 10 countries in terms of business English proficiency (see bei.globalenglish.com). The questionnaire for the German participants was prepared using backward translation procedures.

\footnotetext{
${ }^{2}$ The percentage of participants that failed to remember whether the scenario concerned online or offline shopping (study 1) or whether they received apology on Twitter publicly or privately (study 2 ) did not differ between conditions $\left(\mathrm{p}_{\min }=.66\right)$.
} 
Participants were asked to imagine themselves in a service failure situation that involved delivery of a wrong product. Such scenarios are often used to study service failures (e.g., [57; 64]). Scenarios provide control, standardization and ability to focus subjects' attention on important factors [3] and help avoid undesirable response biases due to memory lapses, rationalization tendencies and consistency factors which are common in self-reports of past service failures [57]. Reassuringly, observations in scenario-based experiments hold up in real life [45].

We used the service failure context of a wrong product delivered for three reasons: 1) it is clearly the online retailer that is responsible and no other third party (e.g., delivery company, manufacturer...); 2) customer systematically complain to the online retailer in such a case; and 3) delivery problems are by far the most frequent types of online service failures and the delivery of a wrong item/size is the second most frequent problem overall of all delivery problems in online shopping [28; 62].

Participants were exposed to the service failure scenario either in offline retail store or online shopping. Specifically, they were asked to imagine the purchase of a tablet computer either from an electronics supermarket retailer or an online store. Participants received the wrong tablet, after which they complained to the service provider. In the offline condition, participants visited the Customer Service Desk located in the retail store. In the online condition, participants send an email to the online store's customer service department. In the company's response to the complaint, participants received an apology provided by either a high or low-status personnel. Participants in the offline high-status condition received in-person verbal apology from the General Manager of the store while those in low-status condition received in-person verbal apology from a Customer Care associate. Participants in the online high-status condition 
received email apology from the General Manager of customer service sent from his official email address, while those in the low-status condition received email apology from a Customer service agent sent from a general Customer Service email address. All the participants were told by the company that they would receive their correct replacement order free of charges, which ultimately was the case.

\section{Measures}

Participants were asked to fill in a survey after reading the scenario, Table 1 lists the measures. Informational justice was measured using a scale adapted from Colquitt [7].

Distributive and procedural justice were adapted from Smith et al. [57] and del Rio-Lanza et al. [12]. All scales used 7-point Likert scales. Several questions served as manipulation checks. Participants were asked whether they received an apology from high status personnel, and whether they shopped from offline retail store or online. We also measured scenario realism using scales adapted from Van Vaerenbergh, Vermeir, and Larivière [66]. In order to establish that the differences in the cultural orientations of the two countries (Germany and India) do indeed conform to their scores in the national Hofstede index [25], we also measured power distance and individualism-collectivism at the individual level using scales by Yoo and Donthu [72]. Lastly, participants were asked to provide some demographic information. All final scores were computed using the averages of the items scores. As shown in Table 1, all measures demonstrated sufficient internal consistency (all Cronbach's $\alpha$ values $>.70$ ).

[Table 1 here.] 


\section{Results}

\section{Manipulation and Realism Checks}

All manipulations work as intended. T-tests show that both German and Indian participants in the high-status apology condition perceive that the service personnel had higher status compared to participants in the low-status apology condition $\left(M_{\text {German High Status }}=5.29\right.$, $M_{\text {German Low Status }}=3.69, t(194)=8.29, p<.001 ; M_{\text {Indian High Status }}=5.54, M_{\text {Indian Low status }}=4.11, t(194)$ $=7.05, p<.001)$. As expected from the national scores in Hofstede index [25], Indian participants exhibited higher power distance and collectivism than German participants $\left(M_{\text {Indian }}\right.$ Power Distance $=3.60, M_{\text {German Power Distance }}=3.11, t(390)=3.90, p<.001 ; M_{\text {Indian Collectivism }}=5.27$, $\left.M_{\text {German Collectivism }}=4.89, t(390)=4.06, p<.001\right)$. Furthermore, the scenarios were considered realistic $(M=5.71)$. Analysis of Variance using realism as a dependent variable reveals that the 3 factors (status, channel and culture) do not have significant main or interaction effects, except for main effect of status. Adding scenario realism as a covariate to the analyses did not significantly alter the significance or directionality of the results.

\section{Main results}

A full factorial ANOVA using informational justice as dependent variable reveals a significant 3-way interaction between status of service personnel, complaint channel and national culture $(F(1,384)=6.02, p<.05)$. Figure 2 illustrates the three-way interaction effect and Table 2 details the ANOVA results. A 2 (status of service personnel) x 2 (complaint channel) ANOVA on the Indian sample shows, as expected, a significant 2-way interaction between status and complaint channel $(F(1,192)=6.17, p<.05)$. For the offline context, t-tests show that Indian participants perceived higher informational justice in the high apology status condition $(M=$ $5.25, S D=1.23)$ than in the low apology status condition $(M=4.66, S D=1.22, t(103)=2.42, p$ 
$<.05$ ), while for the online e-mail context participants had similar informational justice perceptions in the high status $(M=4.70, S D=1.10)$ and low status conditions $(M=4.98, S D=$ 1.27, $t(89)=1.13, p=.26$ ). These findings support H1a. For the German sample, a 2 (status of service personnel) $\mathrm{x} 2$ (complaint channel) ANOVA shows, as expected, that there was no significant 2-way interaction between status and complaint channel $(F(1,194)=1.66, p=.20)$. In both the offline and the online channels, t-tests show that German participants had similar informational justice perceptions in high status and low status conditions (offline: $t(92)=1.35, p$ $=.18$; online: $t(100)=.25, p=.81)$. These findings support $\mathrm{H} 1 \mathrm{~b}$.

[Figure 2 and Table 2 here]

\section{Results on Procedural and Distributive Justice}

While no formal hypotheses were advanced on the other dimensions of justice, we also performed full factorial ANOVAs on procedural and distributive justices (see Table 2 for the detailed results). We found marginally significant 3-way interactions between status, complaint channel and national culture, for both procedural justice $(F(1,384)=3.32, p=.069)$ and distributive justice $(F(1,384)=3.67, p=.056)$. Because the 3-way interactions were marginally significant we decomposed them for both justices. For procedural justice, 2 (status of service personnel) x 2 (complaint channel) ANOVAs on, respectively, the Indian and the German samples show non-significant 2-way interactions between status and complaint channel (India: $F(1,192)=1.09, p=.30$; Germany: $F(1,192)=2.37, p=.13)$. For both Indian and German participants and for both offline and online contexts, all t-tests show that perceived procedural justice perception did not differ between the high and low apology status conditions $\left(t_{\min }=1.56\right.$, $p_{\min }=.12$ for the German participants in the offline context). Status of the service personnel thus doesn't influence procedural justice perception. These results are consistent with the 
aforementioned rational that procedural justice doesn't encompass the human part of service recovery.

For distributive justice, 2 (status of service personnel) x 2 (complaint channel) ANOVAs on, respectively, the Indian and the German samples also show non-significant 2-way interactions between status and complaint channel (India: $F(1,192)=1.95, p=.17$; Germany: $F(1,192)=1.74, p=.19)$. As was the case for procedural justice, distributive justice perception did not significantly differ between the high and low apology status conditions. The status of the service personnel does not influence distributive justice, which is again consistent with the aforementioned rational that distributive justice doesn't encompass the human part of service recovery.

\section{Discussion}

Study 1 shows that Eastern customers are sensitive to the status of the service personnel but only in an offline complaint channel and not in an online channel. In contrast, Western customers are indifferent to the status of the service personnel, regardless of the complaint channel. These results in an offline complaint channel are in line with the findings of Patterson et al. [50], but also confirm that service recovery findings from previous offline research are not simply generalizable to online contexts [28]. Study 2 further develops these findings by outlining the conditions under which the service provider's status might matter in an online context. In particular, we examine whether the public versus private nature of the apology matters for Eastern and Western customers. Study 2 also examines the moderated mediation role of informational justice on recovery satisfaction across Eastern and Western cultures. 


\section{Study 2}

\section{Design and Participants}

In an effort to improve reliability and to increase generalizability, Study 2 collected data from two Western countries (Germany and United States) and two Eastern countries (Philippines and India) [2]. Like Germany and India, the United States and Philippines have contrasting scores in Hofstede's national scores [25] on power distance and individualism-collectivism. The United States' and the Philippines' power distance score is 40 and 94, respectively, while their individualism-collectivism score is 91 and 32, respectively. While the two Eastern and two Western countries selected are similar in terms of power distance and individualism, they differ on other cultural value dimensions like long-term orientation and indulgence [26; 27]. This sampling strategy will thus strengthen the fact that the cultural dimensions of power distance and individualism drive the observed effects [2].

Three hundred eighty-three participants from the two Western countries (187 from Germany, 196 from the United States; $68 \%$ male; $\mathrm{M}_{\mathrm{age}}=33.2$ years, $\left.\mathrm{SD}=11.6\right)$ and 446 participants from the two Eastern countries (161 from Philippines and 285 from India; 69\% male; $\mathrm{M}_{\text {age }}=32.4$ years, $\mathrm{SD}=9.3$ ) participated in a 2 (status of service personnel: high vs. low) x 2 (apology mode: public vs. private) x 2 (culture: Western vs. Eastern) between-subject experiment. Participants were recruited from Crowdflower crowdsourcing platform (www.crowdflower.com). Participants were paid \$1.40 (Germany and United States) and \$1.20 (India and Philippines) in exchange for their participation. Eleven participants from the German sample, 10 from the United States sample, 16 from the Indian sample and 7 from the Philippines sample were removed from the analyses as they failed to remember whether they received 
apology on Twitter publicly or privately. The significance and directionality of our results hold when these participants are not removed from the analyses.

Respondents were asked to imagine a service failure and recovery episode on Twitter. This social medium was a natural choice for the study scenarios as, globally, Twitter is the preferred social media channel for service complaints [42]. To ensure the realism of our results, only those Crowdflower contributors who had shopped online at least once in the last 6 months, had an active Twitter user account and had tweeted something during the last 2 months, were allowed to participate in this study.

\section{Procedure}

For participants from the USA, India and Philippines, the survey was presented in English, while for the German participants it was presented in German (using both forward and backward translation by bilingual authors). The use of English as the survey language in Philippines is appropriate as 2013 Pearson BEI Survey [51] that ranks countries in terms of Business English proficiency ranked Philippines among the top 5 countries (bei.globalenglish.com). All participants were asked to imagine buying online a tablet computer from the XYZe-shop. After receiving the wrong model, the customers tweeted their complaint to the official Twitter customer service handle of the company: “@XYZe-shopHelp I received the wrong model of the table computer that I ordered. This model is old and cheaper. You guys have the worst service!". The participants then read the company's response, which included "I am really sorry and sincerely apologize for the inconvenience caused. Pl. send me the order details so I can personally follow up". This message was either sent by the head of customer service (high status condition) or a customer service agent (low status condition) as a direct reply to the customer's tweet (public condition), or using the 'direct message (DM)' option on Twitter 
(private condition). All tweets had the typical Twitter lay-out in order to increase the realism of the study. All participants were informed by the company that they would receive their correct replacement order free of charges, which ultimately was the case.

\section{Measures}

Table 1 lists all the measurement scales. Informational, distributive and procedural justice were measured using the same scales as in Study 1. In order to further confirm the central role of informational justice (over all other justice dimensions), we also assessed interpersonal justice, the second dimension of interactional justice, with two items adapted from Colquitt [7]. Recovery satisfaction was measured using scales adapted from Goodwin and Ross [16] and Smith et al. [57]. All items were measured using 7-point Likert scales. As manipulation checks, we asked participants whether they got an apology from a high-status personnel and if they received a public or private apology. We also performed a realism check by asking participants how realistic they found the situation, how realistic they found the tweet exchange between them and the company, and if they agreed that the situation described was believable $(\alpha=.72)$ using a scenario realism scale adapted from Van Vaerenbergh et al. [66]. Like in study 1, we also measured power distance and individualism-collectivism at the individual level. Lastly, we assessed demographic variables. All final scores were again computed using the averages of the items scores. All Cronbach's $\alpha$ values exceed the recommended 0.70 threshold (see Table 1).

\section{Results}

\section{Manipulation and Realism Checks}

The manipulations worked as intended. T-tests showed that participants in the high-status apology condition perceived that the service personnel had higher status compared to participants in the low-status apology condition $\left(M_{\text {German High Status }}=5.20, M_{\text {German Low Status }}=4.01, t(174)=5.36\right.$, 
$p<.001 ; M_{\text {US High Status }}=5.39, M_{\text {US Low Status }}=4.61, t(184)=4.33, p<.001 ; M_{\text {Indian High Status }}=5.65$, $M_{\text {Indian Low status }}=4.85, t(267)=5.08, p<.001 ; M_{\text {Philippine High Status }}=5.58, M_{\text {Philippine Low Status }}=4.64$, $t(152)=412, p<.001)$. As expected from the national scores in Hofstede index [25], Eastern participants reported significantly higher means of power distance cultural orientation $(\mathrm{M}=3.75)$ as compared to Western participants $(M=3.21 ; t(783)=5.252, p<.001)$. Eastern participants also reported significantly higher means of collectivism $(M=5.34)$ as compared to Western participants $(M=4.90 ; t(783)=6.034, p<.001)$. Participants also considered the scenarios realistic $(M=5.78)$. Full factorial ANOVA results show that the three factors (status, mode and culture) do not have either significant main or interaction effects on scenario realism.

In order to justify the pooling of the two Eastern (i.e., India and Philippine) and of the two Western countries (i.e., Germany and US), we performed two 2 (apology status) x 2 (apology mode) $\mathrm{2} 2$ (country) full factorial ANOVAs on each justice dimension, with just the two Eastern countries on one hand and just the two Western countries on the other hand. All ANOVAs indicated that the country factor was not involved in any significant interaction (all Fs $<1)$. This indicates that the results are not significantly different between the two Eastern countries on one hand, and between the two Western countries on the other hand ${ }^{3}$.

\section{Main Results}

The second hypothesis proposed that Eastern customers will have higher informational justice perceptions in online social media context when apologized by high status as compared to low status personnel but only when the apology is provided publicly, not when it is provided privately, whereas apology status and apology mode would not make a difference for Western customers. The results of a full factorial ANOVA using informational justice as the dependent

\footnotetext{
${ }^{3}$ We also checked and found that all results hold at the country level.
} 
variable shows a significant 3-way interaction between apology status, apology mode and national culture $(F(1,777)=6.49, p=.01)$. Figure 3 displays the interaction effect and Table 3 details the ANOVA results.

A 2 (status of service personnel) x 2 (apology mode) ANOVA on Eastern participants shows, as expected, a significant two-way interaction effect between apology status and mode of apology $(F(1,419)=10.87, p=.001)$. In case of a public apology, t-tests show that Eastern participants perceived higher informational justice in the high status condition $(M=6.26, S D=$ $0.67)$ than in low status condition $(M=5.76, S D=0.82 ; t(214)=4.85, p<.001)$, while for a private apology Eastern participants had similar informational justice perceptions in high apology status $(M=5.80, S D=0.89)$ and low apology status conditions $(M=5.82, S D=0.82$; $t(205)=0.17, p=.87$ ). These findings support H2a. A 2 (status of service personnel) $\times 2$ (apology mode) ANOVA on Western participants shows, as expected, a non-significant 2-way interaction between apology status and apology mode $(F(1,358)=0.42, p=.52)$. For both public and private apology, t-tests show that Western participants had similar informational justice perceptions in high status $\left(M_{\text {public }}=5.48, S D_{\text {public }}=1.05, M_{\text {private }}=5.60, S D_{\text {private }}=1.00\right)$ and low status conditions $\left(M_{\text {public }}=5.60, S D_{\text {public }}=0.94, M_{\text {private }}=5.59, S D_{\text {private }}=0.92 ;\right.$ public: $t(184)=$ $0.85, p=.40$, private: $t(174)=.07, p=.94)$. These findings support $\mathrm{H} 2 \mathrm{~b}$.

[Figure 3 and Table 3 about here]

The third hypotheses (a moderated mediation) was tested using model 12 of the PROCESS regression-based macro developed by Hayes [19]. Recovery satisfaction served as dependent variable, status of the service personnel as the independent variable (coded 0 for low status and 1 for high status) and informational justice as the mediating variable. Apology mode (coded 0 for private apology and 1 for public apology) served as a moderator of the relationship 
between status of the service personnel and informational justice, and national culture (coded 0 for Eastern and 1 for Western) further moderated this moderation (cf. Figure 1). We thus tested for the mediating effect of informational justice in four conditions (cf. Table 4). All mediation results reported in this study used 10,000 bootstrapping samples with 95\% bias corrected confidence intervals (CI). Table 4 lists the results. As expected, informational justice mediated the effect of status of the service personnel on recovery satisfaction for Eastern participants that were offered a public apology, but not when they were offered a private apology. For Western customers, informational justice did not mediate the effect of status on recovery satisfaction, and that both when the apology was provided publicly and privately. These results support both H3a and $\mathrm{H} 3 \mathrm{~b}$.

We also assessed and confirmed that the third hypotheses hold when controlling for the effects of the other dimensions of justice. For that, we tested the moderated mediation model (model 12 in PROCESS) using procedural, distributive and interpersonal justice as covariates on recovery satisfaction. As expected, informational justice still mediated the indirect effect of apology status on recovery satisfaction only for Eastern participants who receive a public apology (effect $=.10,95 \% \mathrm{CI}, .0442$ to .1828$)$.

\section{[Table 4 about here]}

\section{Results on the other Dimensions of Justice}

Analogous to study 1, while no formal hypotheses were advanced on the other dimensions of justice, we re-performed the full factorial ANOVAs on distributive, procedural, and interpersonal justice. The results are detailed in Table 3. They show that the 3-way interactions between status of service personnel, apology mode and culture are not significant for these three other dimensions of justices. Because decomposing non-significant interactions is 
inappropriate [31], we further examined the effect of status of the service personnel, our main variable of interest. For the three other dimensions of justice, status of the service personnel had no main effect and was not involved in any significant 2-way interaction (see Table 3). Thus, status of the service personnel does not influence the other dimensions of justice and that whatever the level of the other factors (i.e., apology mode and culture). For procedural and distributive justices, the non-significant effects of status of service personnel are consistent with the findings of study 1 and with the rational that procedural and distributive justices do not encompass the human part of service recovery. For interpersonal justice the non-significant effect of status of service personnel is consistent with the rational that the lack of interpersonal cues in an online context reduces the relevance of interpersonal justice in an online context [68].

\section{Discussion of the Study}

In an online context, Eastern customers perceive higher levels of informational justice and recovery satisfaction when offered apology from high status service personnel as compared to low status service personnel in public, but not in private. Western customers are indifferent to the apology status of service personnel in public or private mode. These findings provide more insights into the mechanisms associated with apology status, showing that the positive effects of having a high-status employee responding to an online complaint only occur if this response is visible to other in-group members.

\section{General Discussion}

\section{Theoretical Contributions}

The combined results of two studies contribute to a coherent picture, in which the effectiveness of the status of the apologizing personnel depends on both culture and the channel through which it is offered. With these findings, this paper contributes to the literature in two 
ways. First, our findings support the notion that service recovery strategies proposed and tested in an offline context cannot be transferred to an online context [48]. More precisely, this paper shows that while the apologizer's status matters for Eastern customers in an offline channel, this apologizer's status does not matter in a traditional online complaint handling context (e.g. via email). These results give a better understanding of service recovery across online and offline channels [28], which is especially relevant given that research on service recovery in online shopping context is still in its infancy [69] despite the increasing number of online transactions [1].

Second, this paper uncovers a valuable boundary condition to the effects of apology status on customer outcomes. The findings show that a public apology from a high-status service provider conveyed through social media (Twitter) resulted in higher justice perceptions for customers in Eastern cultures. On the contrary, when the apology was given privately, Eastern customers were indifferent to the apology status of service personnel. For Western customers, as expected because of the irrelevance of the face concept in cultures that are known to be individualistic with low power distance, the apology status did not matter. These findings illustrate that the public nature of an apology drive the apology status' effects, rather than the type of channel in itself. They also provide a better understanding on how to handle social media complaints [36]. In particular, depending on who is offering the apology and the consumers' cultural background, service providers may apologize using the direct message option or using a direct reply to customers' online complaints.

\section{Managerial Implications}

The findings of this paper are relevant to global managers of online retailing companies. We find that in case of such complaints, in order to improve customer evaluations, managers or 
their employees need to respond depending on the cultural background of the customer. While we suggest that for Eastern customers, a manager or higher-level employee apologize publicly on social media, we would like to distinguish between firms depending on their size. This is because for effective complaint management it would be reasonable to suggest that for a smaller firm the manager or owner could apologize, for example a small hotel owner or manager of a small boutique, because of the likelihood of lower volume of complaints. However, for a large corporation like an online superstore or a multinational telecom company, it might not be practical to suggest that the manager be involved in each and every complaint redressal primarily because of the likely large volume of complaints.

The effective way to address this issue could be to look at a particular segment within the complaining customers based on their value in terms of RFM (Recency, Frequency and Monetary value). This data would be relatively easy for e-commerce service providers to analyze as most of them would be having an existing database tracking their customers' purchase history and website visits. They could additionally incorporate social media engagement data, which is also easy for online firms to collect, when segmenting such social media complainers. For example, for customers who are more active on social media with large number of Twitter followers, firms could choose to let managers respond to them publicly as that could convey to all online customers about the firm's seriousness in handling complaints and thus improve their brand image. Also firms could choose to let the frontline employees respond to all complaints initially. But after that, on the basis of RFM and social media engagement, complaints could selectively be handled by the managers in public domain.

While we suggest responding to Twitter complaints publicly (for Eastern customers), it is understandable that not all complaints can be addressed in 140 characters because of complexity. 
This could be even truer in case of financial services because of information security and privacy issues. It would therefore be advisable to move the conversation privately (by direct message option) after the initial public apology and then get back to public domain in case of successful resolution for everyone to see. In Eastern collectivist societies, this would likely ensure a favorable opinion about the firm's complaint resolution practices.

\section{Limitations and Future Research}

The current examination carries several limitations that serve as opportunities for future research. First, this study used scenario-based experiments instead of using actual consumption experiences. Future studies could use field data involving real-life consumption. Second, this paper used the online service failure context of a wrong product getting delivered as faulty deliveries are considered among the most common problems faced by online shoppers [28; 62]. However, to increase the generalizability of our findings, future research might examine other online service failure contexts like late arrival of the product, damaged product or no-show of goods and might also examine eventual specificities of high value products (high-end laptop) versus low value products. Third, this paper considered only complaints send to the organization in general, yet some customers prefer to complain to the manager directly [10]. Future research might examine whether a response from the manager increases customer evaluations of the apology or not. Likewise, researchers might examine whether letting an employee respond to a complaint addressed to the manager decreases recovery evaluations.

Fourth, to compensate the weakness of the specific interactional part of justice in ecommerce environment, it appears that online firms try to enhance the overall customer experience through the implementation of innovative tools that should increase other types of justice (i.e., procedural and/or distributive justice, but also the informational part of interactional 
justice). Future research could, for instance, examine the increasing use of artificial intelligence powered virtual assistants in online shopping websites or of predictive support systems which enable the service provider to (i) anticipate customer problems, (ii) proactively work on solving them, and (iii) keep the customer informed through active notifications about the status of the complaint resolution $[56 ; 58]$. Fifth, we obtained in an online service context that in Eastern cultures status matters when the apology is provided publicly but not when the apology is provided privately. Future research could assess whether this finding replicates in an offline context. If so, this result would strengthen the Computers Are Social Actors (CASA) hypothesis [38; 54], further confirming that people attribute to computers (and other devices) human properties and, consequently, that they integrate into their interactions with devices aspects that are relevant for interpersonal interactions. ${ }^{4}$

Finally, this study examined the effects of apologizing publicly versus privately, yet in Study 2 part of the service recovery was happening privately. In particular, customers were asked to provide more information using the direct message option, after which they were told that the product would be replaced free of charges. Future research might examine how customers react to being redirected from the public to the private channel, depending on their motivation to complain online. For example, if a customer wants to take revenge by tweeting the complaint publicly, he or she might prefer to handle the complaint publicly. Future research might also examine whether offering compensation online (especially overcompensation) triggers opportunistic behavior from other customers. In all, it is our vast belief that understanding how organizations can or need to tailor their service recovery activities to the channel used represents an important avenue for future research.

\footnotetext{
${ }^{4}$ We thank an anonymous reviewer for this suggestion
} 


\section{REFERENCES}

1. A.T. Kearney. A.T. Kearney 2013 Global Retail E-commerce Index: Online Retail is Front and Center in the Quest for Growth. https://www.atkearney.com/documents/10192/3609951 (accessed on September 26, 2016).

2. Alden, D., Hoyer, W. and Lee C. Identifying global and culture specific dimensions of humour in advertising: A multinational analysis. Journal of Marketing, 57, (1993), 64-75.

3. Alexander, C.S. and Becker, H.J. The use of vignettes in survey research. Public Opinion Quarterly, 42, (1978), 93-104.

4. Andreasen, A.R. Consumer Complaints and Redress: What We Know and What We Don't Know, In, Maynes, E.S. and ACCI Research Committee, (eds.), The Frontier of Research in the Consumer Interest, Columbia, MO: American Council on Consumer Interests, 1988, 675-722.

5. Chau, E.G. and Gudykunst, W.B. Conflict resolution styles in low- and high-context cultures. Communication Research Reports, 4, (1987), 32-37.

6. Cohen, J. Statistical Power Analysis for the Behavioral Sciences. Hillsdale: Lawrence Erlbaum Associates, 1988.

7. Colquitt, J. On the dimensionality of organizational justice: A construct validation of a measure. Journal of Applied Psychology, 86, 3 (2001), 386-400.

8. Colquitt J.A., Conlon D.E., Wesson M.J., Porter C.O. and Yee, N.K. Justice at the millenium: A meta-analytic review of 25 years of organizational justice research. Journal of Applied Psychology, 86, 3 (2001), 425-445.

9. Crisafulli, B. and Singh, J. Service failures in e-retailing: Examining the effects of response time, compensation, and service criticality. Computers in Human Behavior, (2017), In press. 
10. Cunliffe, M. and Johnston, R. Complaint management and the role of the chief executive. Service Business, 2, 1 (2008), 47-63.

11. Davidow, M. The bottom line impact of organizational responses to customer complaints. Journal of Hospitality and Tourism Research, 24, 4 (2000), 473-90.

12. Del Río-Lanza, A.B., Vázquez-Casielles, R. and Díaz-Martín, A.M. Satisfaction with service recovery: Perceived justice and emotional responses. Journal of Business Research, 62, 8 (2009), $775-781$.

13. Donthu, N. and Yoo, B. Cultural influences on service quality expectations. Journal of Service Research, 1, 2 (1998), 178-186.

14. Forbes. 4 Steps From Customer Anger To Customer Loyalty: The Expert Customer Service Recovery Method. (2014) https://www.forbes.com/sites/micahsolomon/2014/07/16/customerservice-recovery/\#779c49d45fc6 (accessed on May 29, 2017).

15. Gelbrich, K. and Roschk, H. A meta-analysis of organizational complaint handling and customer responses. Journal of Service research, 14, 1 (2011), 24-43.

16. Goodwin, C. and Ross, I. Consumer responses to service failures: Influence of procedural and interactional fairness perceptions. Journal of Business Research, 25, 2 (1992), 149- 63 17. Grove, S.J. and Fisk, R.P. The impact of other customers on service experiences: A critical incident examination of 'getting along'. Journal of Retailing, 73, 1 (1997), 63-85.

18. Hall, E. Beyond Culture. New York: Doubleday, 1976.

19. Hayes, A.F. Introduction to Mediation, Moderation, and Conditional Process Analysis. New York: The Guilford Press, 2013.

20. He, Y., Chen, Q and Alden. D.L. Consumption in the public eye: The influence of social presence on service experience. Journal of Business Research, 65, 3, (2012), 302-310. 
21. Heine, S.J. Constructing Good Selves in Japan and North America, In, Sorrentino, R., Cohen, D., Olson, J. and Zanna, M., (eds.), Culture and Social Behavior, Mahwah: Erlbaum, 2005, pp. 95-116.

22. Hennig-Thurau, T., Malthouse, E.C., Friege, C., Gensler, S., Lobschat, L., Rangaswamy, A. and Skiera, B. The impact of new media on customer relationships. Journal of Service Research, 13, 3 (2010), 311-330.

23. Ho, D. On the concept of face. American Journal of Sociology, 81, 4 (1976), 867-884.

24. Ho, S.S. and McLeod, D.M. Social-psychological influences on opinion expression in faceto-face and computer-mediated communication. Communication Research, 35, (2008), 190-207. 25. Hofstede, G. Cultures and Organization: Software of the Mind. Berkshire: McGraw-Hill, 1991.

26. Hofstede, G. Culture's Consequences: Comparing Values, Behaviors, Institutions, and Organizations Across Nations. Second Edition, Thousand Oaks CA: Sage Publications, 2001. 27. Hofstede, G., Hofstede, G.J. and Minkov, M. Cultures and Organizations: Software of the Mind. Revised and Expanded 3rd Edition, Berkshire: McGraw-Hill, 2010.

28. Holloway, B.B. and Beatty, S.B. Service failure in online retailing. Journal of Service Research, 6, 1 (2003), 92-105.

29. Hui, M.K. and Au, K. Justice perceptions of complaint-handling - a cross-cultural comparison between PRC and Canadian customers. Journal of Business Research, 52, 2 (2001), $161-173$.

30. Kees, J., Berry, C., Burton, S. and Sheehan, K. An analysis of data quality: Professional panels, student subject pools, and Amazon's Mechanical Turk. Journal of Advertising, 46, 1 (2017), 141-55. 
31. Keppel, G and Wickens, T. Design and Analysis: A Researcher's Handbook. 4th edition, Prentice Hall, 2004.

32. Kim, T.Y., Dekker, R. and Heij, C. Cross-Border Electronic Commerce: Distance Effects and Express Delivery in European Union Markets. International Journal of Electronic Commerce, 21, 2 (2017), 184-218.

33. Kim, Y.H., Cohen, D. and Au, W.T. The jury and abjury of my peers: The self in face and dignity cultures. Journal of Personality and Social Psychology, 98, 6 (2010), 904-916.

34. Knox G. and Van Oest, R. Customer complaints and recovery effectiveness: A customer base approach. Journal of Marketing, 78, 5 (2014), 42-57.

35. Kumar, V., Pozza, I.D. and Ganesh, J. Revisiting the satisfaction-loyalty relationship: Empirical generalizations and directions for future research. Journal of Retailing, 89, 3 (2013), 246-262.

36. Larivière, B., Joosten, H., Malthouse, E.C., van Birgelen, M., Aksoy, P., Kunz, W.H. and Huang, M.-H. Value fusion: The blending of consumer and firm value in the distinct context of mobile technologies and social media. Journal of Service Management, 24, 3 (2013), 268-293. 37. Lee, I., Choi, B., Kim, J. and Hong, S-J. Culture-technology fit: Effects of cultural characteristics on the post-adoption beliefs of mobile internet users. International Journal of Electronic Commerce, 11, 4 (2007), 11-51.

38. Lee, J.E.R. and Nass, C.I. Trust in Computers: The Computers-Are-Social-actors (CASA) Paradigm and Trustworthiness Perception in Human-Computer Communication, In, Latusek, D. and Gerbasi, A., (eds.), Trust and Technology in a Ubiquitous Modern Environment: Theoretical and Methodological Perspectives, IGI Global, 2010, pp. 1-15. 
39. Li, J., Konuş, U., Langerak, F. and Weggeman, M.C.D.P. Customer Channel Migration and Firm Choice: The Effects of Cross-Channel Competition. International Journal of Electronic Commerce, 21, 1 (2017), 8-42.

40. Liao, H. Do it right this time: The role of employee service recovery performance in customer-perceived justice and customer loyalty after service failures. Journal of Applied Psychology, 92, 2 (2007), 475-489.

41. Mao, A., Kamar, E., Chen, Y., Horvitz, E., Schwamb, M.E., Lintott, C.J. and Smith, A.M. (2013). Volunteering vs. work for pay: Incentives and tradeoffs in crowdsourcing. 1st AAAI Conference on Crowdsourcing and Human Computation (HCOMP), (2013).

42. Maritz Research. Maritz Research and evolve24- Twitter Study. http://www.maritzresearch.com/ /media/Files/MaritzResearch/e24/ExecutiveSummaryTwitterPo 11.ashx (accessed on July 09, 2016).

43. Massad, N., Heckman, R. and Crowston, K. Customer satisfaction with electronic service encounters. International Journal of Electronic Commerce, 10, 4 (2006), 73-104.

44. Mehrabian, A. Nonverbal Communication. New Brunswick: Transaction Publishers, 1972. 45. Murphy, K.R., Herr, B.M., Lockhart, M.C. and Maguire, E. Evaluating the performance of paper people. Journal of Applied Psychology, 71, (1986), 654-661.

46. Nguyen, A., Heeler, R.M. and Taran, Z. High-low context cultures and price-ending practices. Journal of Product \& Brand Management, 16, 3 (2007), 206-214.

47. Oetzel, J.G. and Ting-Toomey, S. Face concerns in interpersonal conflict: A cross-cultural empirical test of the face negotiation. Communication Research, 30, 6 (2003), 599-624. 
48. Orsingher, C., Valentini, S. and de Angelis, M. A meta-analysis of satisfaction with complaint handling in services. Journal of the Academy of Marketing Science, 38, 2 (2010), 169186.

49. Ostrom, A.L., Parasuraman, A., Bowen, D., Patricio, L. and Voss, C.A. Service research priorities in a rapidly changing context. Journal of Service Research, 18, 2 (2015), 127-159. 50. Patterson, P.G., Cowley, E. and Prasongsukarn, K. Service failure recovery: The moderating impact of individual-level cultural value orientation on perceptions of justice. International Journal of Research in Marketing, 23, 3 (2006), 263 - 277.

51. Pearson English. The 2013 Business English Index \& Globalization of English Report. http://static.globalenglish.com/files/GlobEng_BEIreport\%202013_EN_A4_FINAL.pdf. (accessed on February 21, 2016).

52. Pizzutti, C. and Fernandes, D. Effect of recovery efforts on consumer trust and loyalty in etail: a contingency model. International Journal of Electronic Commerce, 14, 4 (2010), 127-160. 53. Pookulangara, S. and Koesler, K. Cultural influence on consumers' usage of social networks and its' impact on online purchase intentions. Journal of Retailing and Consumer Services, 18, (2011), 348-354.

54. Reeves, B. and Nass, C. The Media Equation: How People Treat Computers, Television, and New Media Like Real People and Places. New York: Cambridge University Press, 1996. 55. Roschk, H. and Kaiser, S. The nature of an apology: An experimental study on how to apologize after a service failure. Marketing Letters, 24, 3 (2013), 293-309.

56. Salesforce.com. 12 customer service tools that will make your customers' lives easier. https://www.salesforce.com/blog/2015/01/12-customer-service-tools-that-will-make-yourcustomers-lives-easier.html (accessed on July 18, 2017). 
57. Smith, A.K., Bolton, R.N. and Wagner, J. A model of customer satisfaction with service encounters involving failure and recovery. Journal of Marketing Research, 36, 3 (1999), 356372.

58. Sourcing Journal. Virtual Assistants Set to Change the Consumer Journey. https://sourcingjournalonline.com/virtual-assistants-set-change-consumer-journey/ (accessed on July 10, 2017)

59. Sparks, B.N. and McColl-Kennedy, J.R. Justice strategy options for increased customer satisfaction in a services recovery setting. Journal of Business Research, 54, (2001), 209-218. 60. Streukens, S. and Andreassen, T.W. Online complaining: Understanding the adoption process and the role of individual and situation characteristics. Managing Service Quality, 23, 1 (2013), 4-24.

61. Tax, S.S., Brown, S.W. and Chandrashekaran, M. Customer evaluations of service complaint experiences: Implications for relationship marketing. Journal of Marketing, 62, 2 (1998), 60-76. 62. The Guardian. Half of online customers experience problems - Which? https:/www.theguardian.com/money/2014/mar/07/half-online-shoppers-problems (accessed on January 11, 2017).

63. Ting-Toomey, S. Toward a theory of conflict and culture, In, Gudykunst, W., Stewart, L. and Ting-Toomey, S., (eds.), Communication, Culture and Organizational Processes, Beverley Hills, CA: Sage, 1985, pp. 71-86.

64. Van Vaerenbergh, Y., De Keyser, A. and Lariviere, B. Customer intentions to invoke service guarantees: Do excellence in service recovery, type of guarantee and cultural orientation matter? Managing Service Quality, 24, 1 (2014), 45-62. 
65. Van Vaerenbergh, Y. and Orsingher, C. Service recovery: An integrative framework and research agenda. Academy of Management Perspectives, 30, 3 (2016), 328-346.

66. Van Vaerenbergh, Y., Vermeir, I. and Larivière, B. Service recovery's impact on customers next-in-line. Managing Service Quality, 23, 6 (2013), 495-512.

67. Voss, C. Rethinking paradigms of service: Service in a virtual environment. International Journal of Operations \& Production Management, 23, 1 (2003), 88-104.

68. Walther J.B. Theories of Computer Mediated Communication and Interpersonal Relations, In, Knapp, M.L. and Daly, J.A., (eds.), The SAGE Handbook of Interpersonal Communication, Thousand Oaks, CA: Sage, 2011, pp. 443-479.

69. Wang, C. and Mattila, A.S. A cross-cultural comparison of perceived informational fairness with service failure explanations. Journal of Services Marketing, 75, 6 (2011), 429-439.

70. Wirtz, J. and Mattila, A. S. The effects of consumer expertise on evoked set size and service loyalty. Journal of Services Marketing, 17, 7 (2003), 649-665.

71. Wong, N.Y. The role of culture in the perception of service recovery. Journal of Business Research, 57, 2 (2004), 957-963.

72. Yoo, B. and Donthu, N. Testing cross-culture invariance of the brand equity creation process. Journal of Product and Brand Management, 11, 6 (2002), 380-398. 
FIGURE 1: Conceptual model of the research

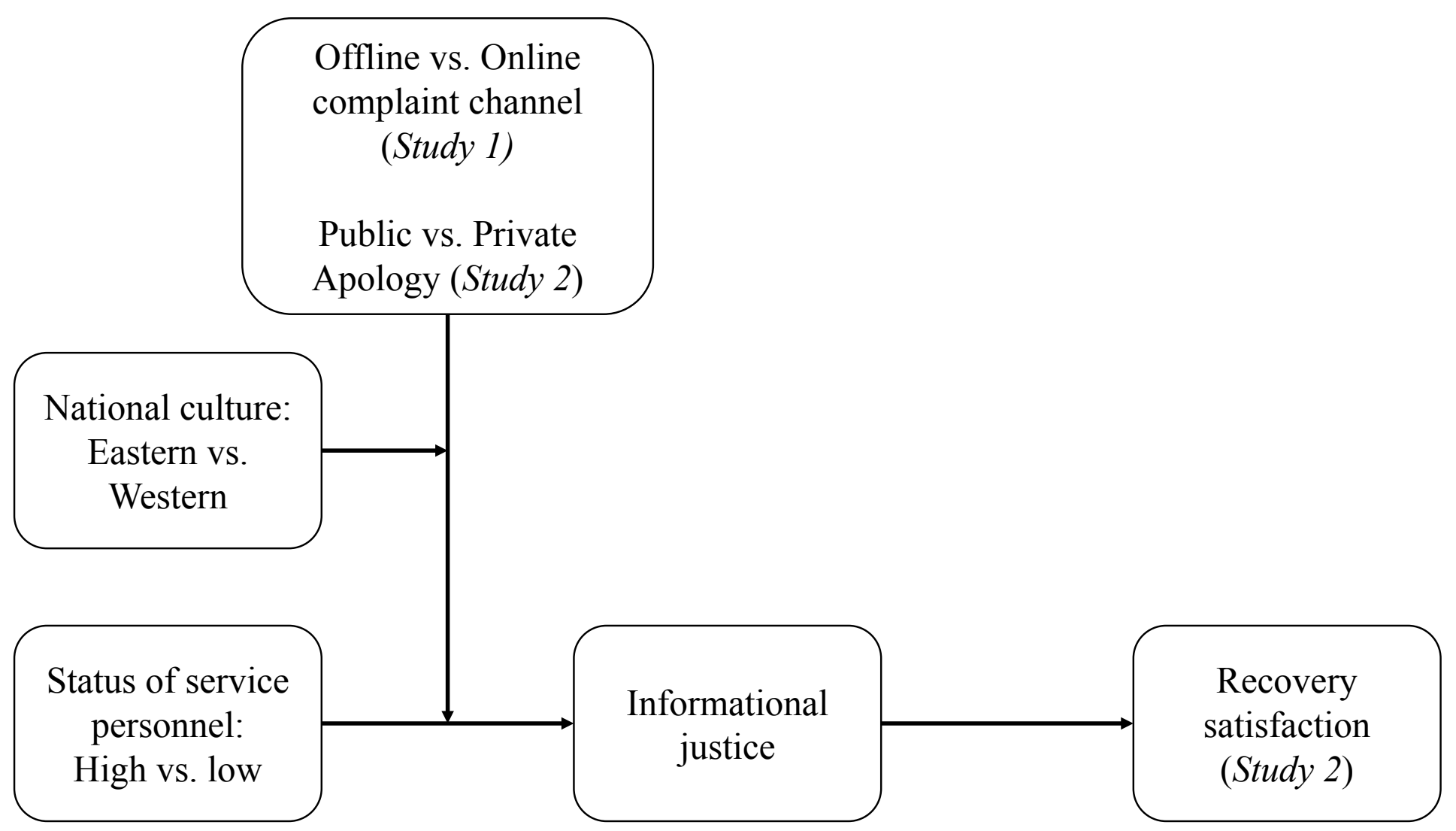


FIGURE 2: Three-way interaction effect of apology status, channel, and culture in study 1

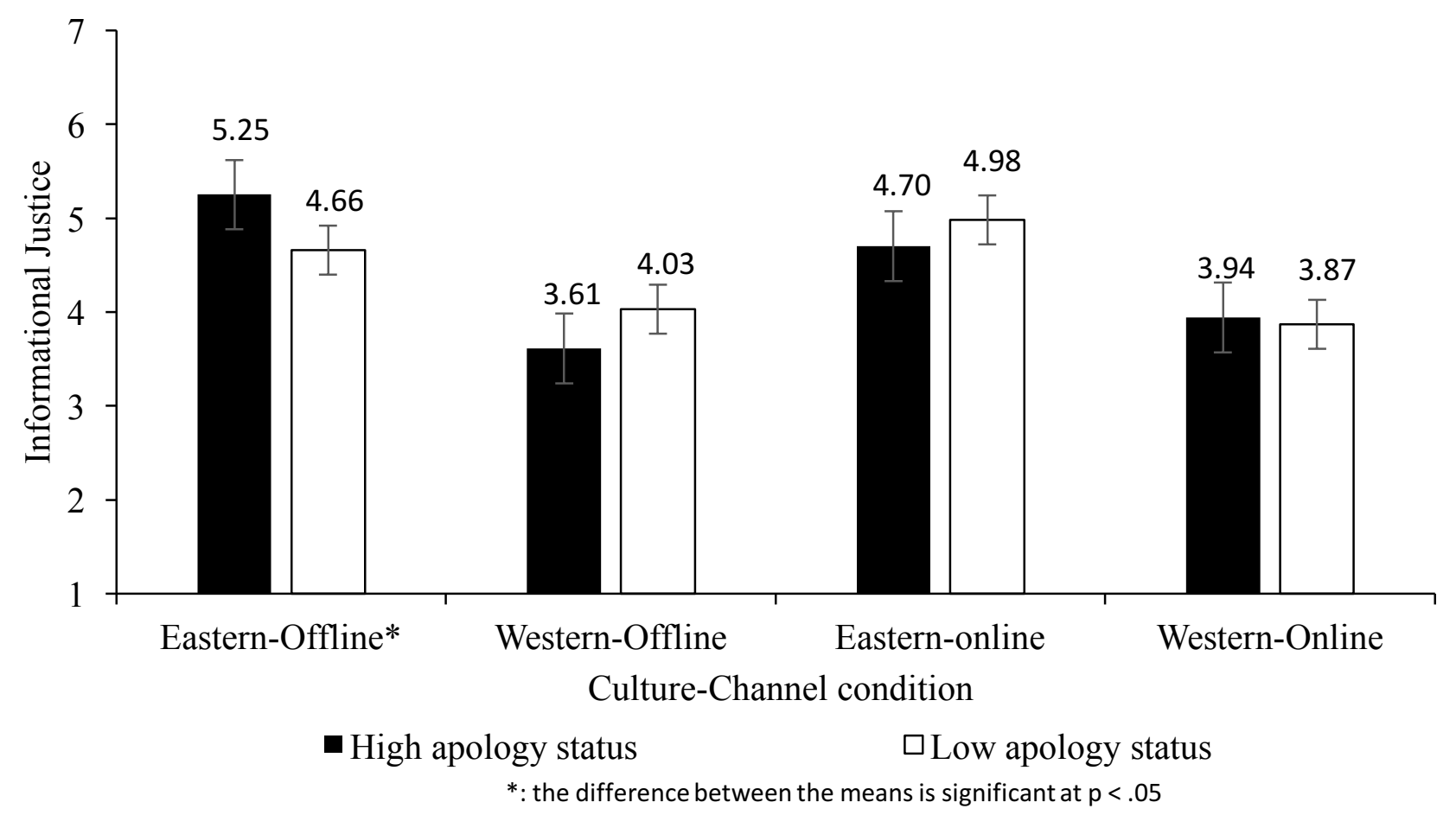


FIGURE 3: Three-way interaction effect of apology status, apology mode, and culture in study 2

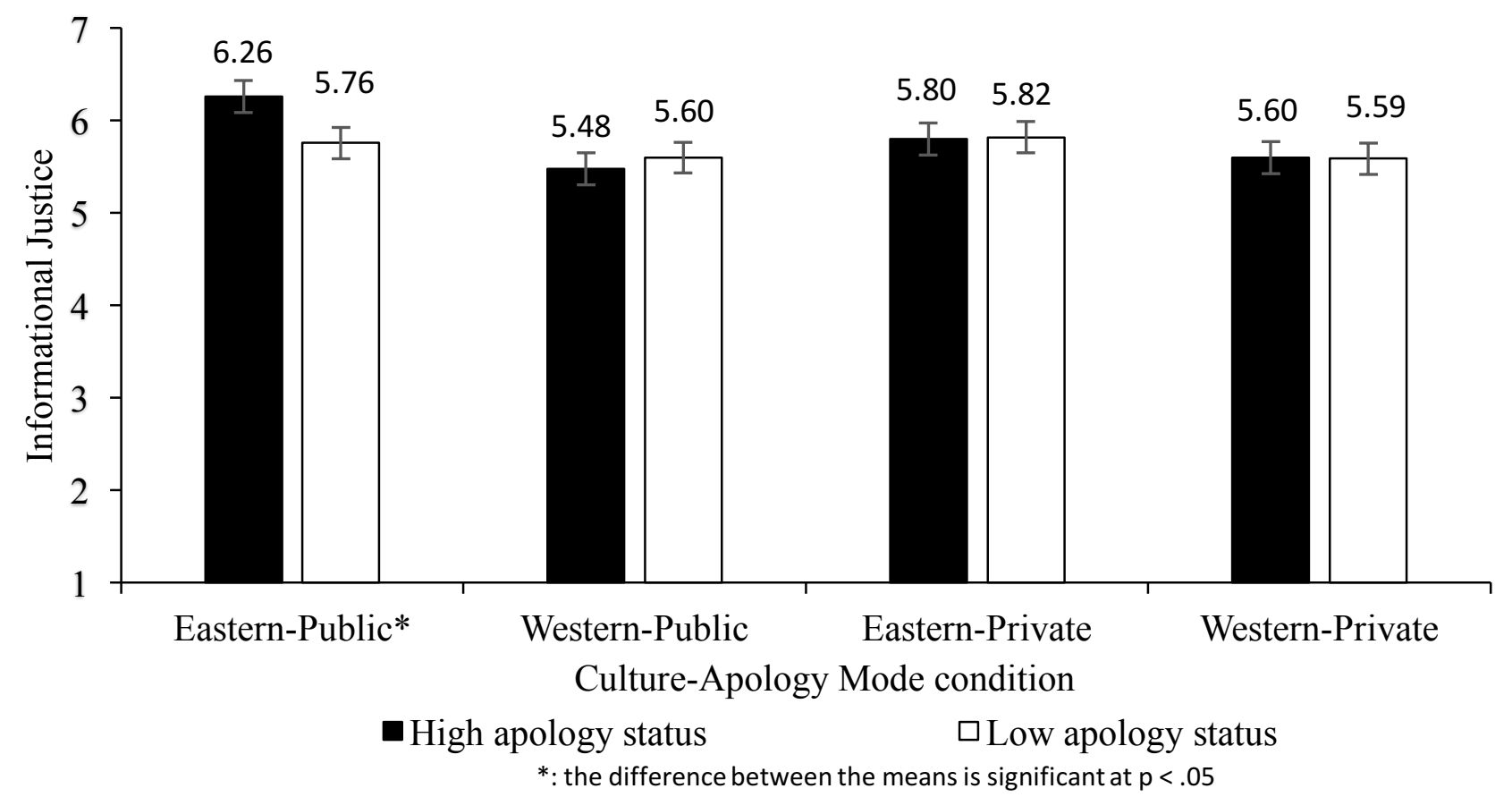




\section{TABLE 1: Measurement scales}

\section{Measurement items}

Distributive justice (Study 1: $\alpha=.85$; Study 2: $\alpha=.94$; adapted from Smith et al. [57])

The outcome I received was fair

I feel that I got what I deserved

In resolving the problem, this [online shopping site/store] gave me what I needed.

This [online shopping site/store] found the right solution to the problem.

Procedural justice (Study 1: $\alpha=.80$; Study 2: $\alpha=.88$; adapted from del Rio-Lanza et al. [12])

I think this online shopping site has good policies and practices for dealing with problems

This online shopping site showed flexibility in dealing with my problem

Informational justice (Study 1: $\alpha=.85$; Study 2: $\alpha=.94$; adapted from Colquitt [7])

The explanations regarding the procedures were reasonable

The Customer Care team explained the procedures thoroughly

The Customer Care team communicated details in a timely manner

The Customer Care team was truthful in their communications with me

Interpersonal justice (Study 2: $\alpha=.94$; adapted from Colquitt [7])

The company employee's communication with me was appropriate

The company employee gave me the courtesy I deserved

Satisfaction with recovery (Study 2: $\alpha=.93$; adapted from Goodwin and Ross [16]; Smith et al. [57])

How satisfied would you be with this online shopping site's handling of the problem? ${ }^{\mathrm{a}}$

I felt the service response I received was good

I am pleased with the service I experienced

Overall, how satisfied would you be with your online shopping experience on this particular occasion? ${ }^{\mathrm{a}}$

Cultural dimensions (adapted from Donthu and Yoo [13]; Patterson et al. [50])

Power distance (Study 1: $\alpha=.80 ;$ Study 2: $\alpha=.90)$

People in higher positions should make most decisions without consulting people in lower positions

People in higher positions should not ask the opinion of people in lower positions too frequently 
People in higher positions should avoid social contact with people in lower positions

People in lower positions should not disagree with people in higher positions

People in higher positions should not delegate important tasks

Individualism/Collectivism (Study 1: $\alpha=.81$; Study 2: $\alpha=.89$ )

Individuals should sacrifice self-interest for the group

Individuals should stick with their group even through difficulties

Group welfare is more important than individual

Group success is more important than individual success

Individuals should only pursue their personal goals after considering group goals

Group loyalty should be encouraged even if individual goals suffer

Notes: Unless noted otherwise, all items were measured on 7-point Likert scales. ${ }^{a}$ anchored by totally not satisfied, totally satisfied. 
TABLE 2: Study 1 ANOVA results

\begin{tabular}{lccccccccc} 
& \multicolumn{2}{c}{ Distributive justice } & \multicolumn{2}{c}{ Procedural justice } & \multicolumn{3}{c}{ Informational justice } \\
\cline { 2 - 10 } Independent variables & $F$ & $p$ & $\eta^{2}$ & $F$ & $p$ & $\eta^{2}$ & $F$ & $p$ & $\eta^{2}$ \\
\hline Apology status (A) & 0.105 & 0.746 & 0.000 & 0.119 & 0.731 & 0.000 & 0.008 & 0.927 & 0.000 \\
Complaint channel (Co) & 3.580 & 0.059 & 0.009 & 2.002 & 0.158 & 0.005 & 0.016 & 0.899 & 0.000 \\
Culture $(\mathrm{Cu})$ & 0.001 & 0.982 & 0.000 & 0.047 & 0.828 & 0.000 & 55.903 & $<0.001$ & 0.127 \\
$\mathrm{~A} * \mathrm{Co}$ & 0.053 & 0.819 & 0.000 & 0.106 & 0.745 & 0.000 & 0.435 & 0.510 & 0.001 \\
$\mathrm{~A} * \mathrm{Cu}$ & 2.182 & 0.140 & 0.006 & 0.546 & 0.460 & 0.001 & 1.394 & 0.239 & 0.004 \\
$\mathrm{Co} * \mathrm{Cu}$ & 2.325 & 0.128 & 0.006 & 0.177 & 0.674 & 0.000 & 0.525 & 0.469 & 0.001 \\
$\mathbf{A} * \mathbf{C o} \mathbf{C u}$ & $\mathbf{3 . 6 7 7}$ & $\mathbf{0 . 0 5 6}$ & $\mathbf{0 . 0 0 9}$ & $\mathbf{3 . 3 2 0}$ & $\mathbf{0 . 0 6 9}$ & $\mathbf{0 . 0 0 9}$ & $\mathbf{6 . 0 2 0}$ & $\mathbf{0 . 0 1 5} *$ & $\mathbf{0 . 0 1 5}$ \\
\hline
\end{tabular}

(*) $\mathrm{p}<0.05$ 
TABLE 3: Study 2 ANOVA results

\begin{tabular}{lccccccccccccc} 
& \multicolumn{2}{c}{ Distributive justice } & \multicolumn{2}{c}{ Procedural justice } & \multicolumn{2}{c}{ Interpersonal justice } & \multicolumn{3}{c}{ Informational justice } \\
\cline { 2 - 12 } Independent variables & $F$ & $p$ & $\eta^{2}$ & $F$ & $p$ & $\eta^{2}$ & $F$ & $p$ & $\eta^{2}$ & $F$ & $p$ & $\eta^{2}$ \\
\hline Apology status (AS) & 1.459 & 0.228 & 0.002 & 0.296 & 0.587 & 0.000 & 0.548 & 0.459 & 0.001 & 2.004 & 0.157 & 0.003 \\
Apology mode (AM) & 0.064 & 0.800 & 0.000 & 0.002 & 0.962 & 0.000 & 0.430 & 0.512 & 0.001 & 1.400 & 0.237 & 0.002 \\
Culture (C) & 6.392 & 0.012 & 0.008 & 4.254 & 0.039 & 0.005 & 14.467 & 0.000 & 0.018 & 29.075 & 0.000 & 0.036 \\
AS*AM & 1.361 & 0.244 & 0.002 & 0.332 & 0.564 & 0.000 & 1.068 & 0.302 & 0.001 & 2.231 & 0.136 & 0.003 \\
AS*C & 1.024 & 0.312 & 0.001 & 0.765 & 0.382 & 0.001 & 0.359 & 0.549 & 0.000 & 5.351 & 0.021 & 0.007 \\
AM*C & 3.542 & 0.060 & 0.005 & 1.681 & 0.195 & 0.002 & 0.454 & 0.501 & 0.001 & 3.820 & 0.051 & 0.005 \\
AS*AM*C & $\mathbf{2 . 4 9 1}$ & $\mathbf{0 . 1 1 5}$ & $\mathbf{0 . 0 0 3}$ & $\mathbf{2 . 6 1 1}$ & $\mathbf{0 . 1 0 7}$ & $\mathbf{0 . 0 0 3}$ & $\mathbf{2 . 4 6 2}$ & $\mathbf{0 . 1 1 7}$ & $\mathbf{0 . 0 0 3}$ & $\mathbf{6 . 4 9 3}$ & $\mathbf{0 . 0 1 1 *}$ & $\mathbf{0 . 0 0 8}$ \\
\hline (*) & & & & & & & & & & & & &
\end{tabular}

$(*) \mathrm{p}<0.05$ 
TABLE 4: Mediation effects of Informational Justice

\begin{tabular}{|c|c|c|c|c|c|}
\hline \multirow[b]{2}{*}{ Culture / apology mode } & \multirow{2}{*}{$\begin{array}{c}\mathbf{b} \\
\text { (indirect) }\end{array}$} & \multirow[b]{2}{*}{ SE(b) } & \multicolumn{2}{|c|}{$\begin{array}{c}\text { Bootstrapped } \\
\text { confidence } \\
\text { intervals }\end{array}$} & \multirow[b]{2}{*}{ Significant? } \\
\hline & & & Lower & Upper & \\
\hline Eastern - public apology & 0.340 & 0.073 & 0.196 & 0.487 & Yes \\
\hline Eastern - private apology & -0.014 & 0.081 & -0.170 & 0.151 & No \\
\hline Western - public apology & -0.086 & 0.101 & -0.288 & 0.106 & No \\
\hline Western - private apology & 0.007 & 0.099 & -0.184 & 0.199 & No \\
\hline
\end{tabular}

Notes: Bootstrapped confidence intervals obtained using 10,000 samples. 